\title{
Coronary artery dissection, traumatic liver and spleen injury after cardiopulmonary resuscitation - a case report and review of the literature
}

Agnieszka Kapłon-Cieślicka1 ${ }^{1}$ Dariusz A. Kosior ${ }^{2,3}$, Marcin Grabowski ${ }^{1}$, Adam Rdzanek ${ }^{1}$, Zenon Huczek ${ }^{1}$, Grzegorz Opolski ${ }^{1}$

$11^{\text {st }}$ Chair and Department of Cardiology, Medical University of Warsaw, Poland 2Mossakowski Medical Research Centre, Polish Academy of Sciences, Warsaw, Poland ${ }^{3}$ Department of Noninvasive Cardiology and Hypertension, Central Clinical Hospital, the Ministry of the Interior, Warsaw, Poland

Submitted: 21 July 2012

Accepted: 7 August 2012

Arch Med Sci 2013; 9, 6: 1158-1161

DOI: 10.5114 /aoms.2013.39235

Copyright (c) 2013 Termedia \& Banach
Corresponding author:

Agnieszka Kapłon-Cieślicka $\mathrm{MD}, \mathrm{PhD}$

$1^{\text {st }}$ Chair and Department of Cardiology

Medical University of Warsaw

1 A Banacha St

02-097 Warsaw, Poland

Phone: +48 600382170

E-mail:

agnieszka.kaplon@gmail.com

Early cardiopulmonary resuscitation (CPR) plays a pivotal role in survival from cardiac arrest. Complications associated with external cardiac compression include trauma to the chest wall, heart and lungs, as well as intra-abdominal injuries.

A 51-year-old woman, a former smoker, was admitted to the University Hospital Emergency Department following an out-of-hospital sudden cardiac arrest preceded by stenocardial pain. Successful CPR of approximately 10 min was immediately applied by a non-professional witness, followed by advanced medical care provided by an ambulance service team. The first recorded rhythm was sinus rhythm with ST-segment elevation in the lateral, inferior and posterior wall leads. Loading doses of aspirin (300 mg) and clopidogrel (600 mg) were administered. While in the ambulance, the patient required defibrillation for ventricular fibrillation. Upon hospital admission the patient was conscious and hemodynamically stable. Coronary angiography revealed a long critical stenosis of the first marginal branch which was identified as the infarct-related artery. Additionally, up to $40 \%$ stenosis of the left anterior descending artery (LAD) was found but considered insignificant. Successful primary coronary angioplasty of the culprit lesion with implantation of two bare-metal stents was performed. Periprocedurally, the patient received $5000 \mathrm{U}$ of unfractionated heparin and a continuous intravenous infusion of abciximab. The patient was transferred to the Intensive Cardiac Care Unit, where initially she remained hemodynamically stable, with no recurrence of chest pain. STsegment elevation resolution was observed.

On the second day of her hospital stay, the patient complained of abdominal pain. The abdomen was tender and rigid on palpation, and peritoneal signs were present. Alanine aminotransferase and aspartate aminotransferase activity rose to $229 \mathrm{U} / \mathrm{l}$ (normal range: 7-56 U/l) and $235 \mathrm{U} / \mathrm{L}$ (normal range: 5-40 U/I), respectively. Hemoglobin concentration decreased from $9.8 \mathrm{~g} / \mathrm{dl}$ on admission to $7.4 \mathrm{~g} / \mathrm{dl}$. Abciximab infusion was discontinued and the patient received a transfusion of $2 \mathrm{U}$ of packed red cells, achieving hemoglobin concentration of $10.3 \mathrm{~g} / \mathrm{dl}$. Abdominal ultrasound examination revealed free intraperitoneal fluid without any other significant abnormalities. A few minutes after the ultrasound examination the patient suffered cardiac arrest due to ventricular fibrillation, which 
was successfully defibrillated. A new ST-segment elevation in V2-V5 leads was recorded. The patient was immediately transported to the Catheterization Laboratory. Coronary angiography showed a total occlusion of the LAD due to a long dissection, which was reopened with three bare-metal stents (Figure 1). The beneficial effect of the marginal branch angioplasty was maintained. Abdominal computed tomography (CT) scan performed directly after the coronary procedure revealed grade IV liver injury (graded according to the American Association for the Surgery of Trauma Liver Injury Scale [1]), with lesions localized predominantly in the left hepatic lobe, spleen lacerations and a hematoma in the peritoneum (Figure 2). There was no evidence of rib or sternal fractures. During the immediate surgical intervention a total splenecto-
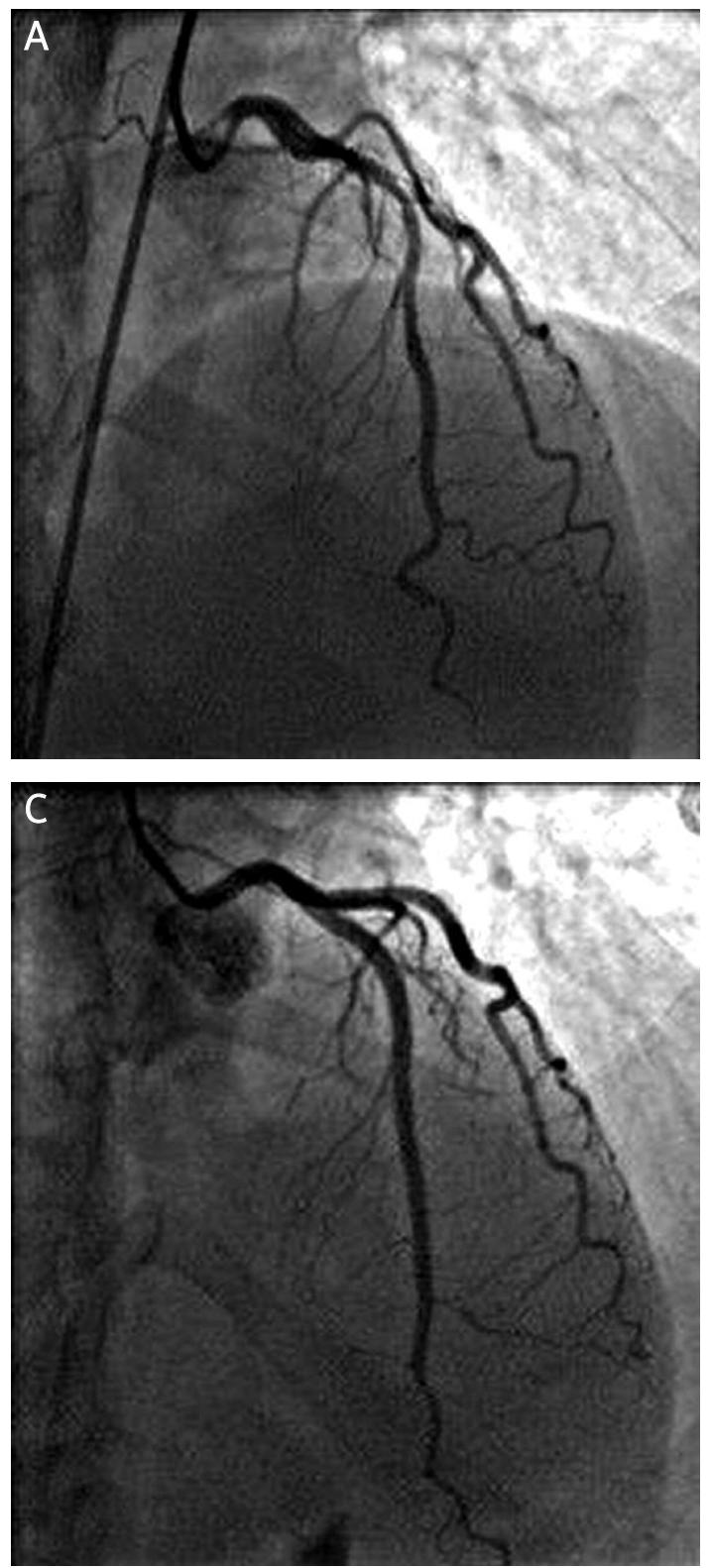

my was performed and bleeding from the liver was stemmed. Histopathological examination of the excised hepatic and splenic tissues was unremarkable. After the surgery, the patient remained conscious and hemodynamically stable. Abdominal ultrasound examination showed only a small amount of intraperitoneal fluid and no new lesions in the liver. Treatment with daily doses of $75 \mathrm{mg}$ of aspirin, $75 \mathrm{mg}$ of clopidogrel and $40 \mathrm{mg}$ of enoxaparin was restarted. The day after the surgical procedure, the patient suffered cardiac arrest due to asystole. She was intubated, mechanically ventilated and received CPR. Adrenaline and atropine were administered in typical doses. A blood sample was collected during resuscitation, revealing a decrease in hemoglobin level from $10.6 \mathrm{~g} / \mathrm{dl}$ to $7.8 \mathrm{~g} / \mathrm{dl}$, and the patient received intravenous fluids.

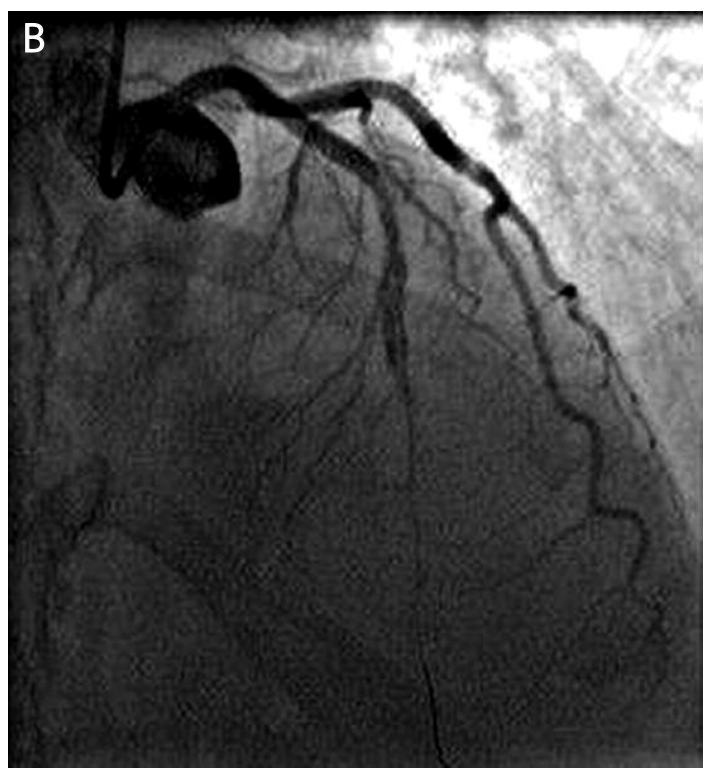

Figure 1. Left descending artery (LAD). A - Initial angiography: LAD with no significant stenosis. B Second angiography: LAD occlusion due to dissection. C - Final result of angioplasty: LAD after implantation of three bare-metal stents 

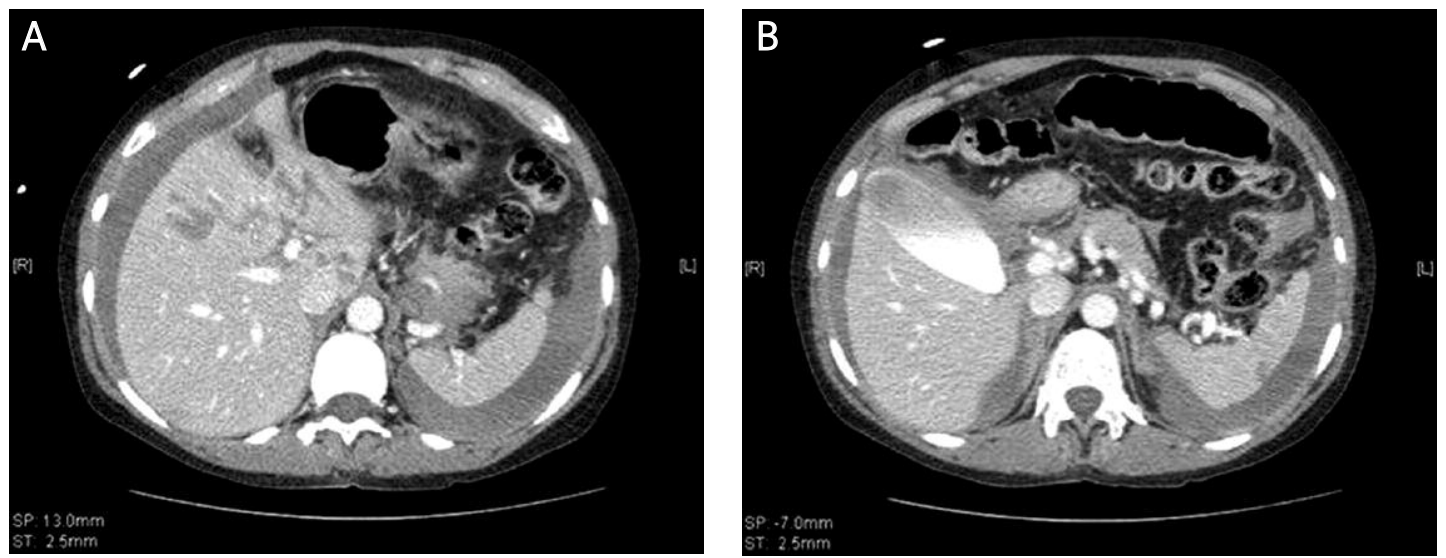

Figure 2. An abdominal CT scan demonstrating hemoperitoneum, liver lacerations (A) and subcapsular lesion in the spleen (B)

After 20 min of sustained asystole despite resuscitation the patient was considered dead. No autopsy was performed.

Rib and sternum fractures are the most common complications associated with CPR. Other thoracic complications include hemothorax, pneumothorax and hemopericardium [2]. Coronary artery dissection has not been described as a CPR complication so far. However, given the angiographic presentation and the timely relation between external chest compressions and the subsequent acute coronary syndrome, we hypothesize that LAD occlusion in our patient might have been a result of traumarelated dissection of the initially diseased vessel wall. Although infrequent, coronary artery dissection after blunt chest trauma has been described previously [3-6].

Intra-abdominal injuries are rare complications of CPR and include hepatic, splenic and intestinal trauma, as well as intraperitoneal bleeding and retroperitoneal hematoma. A review of relevant available publications implies that liver injury is the most common of the CPR-related intra-abdominal complications, with an incidence of approximately $0.6 \%$ [7-13]. Ruptured spleen is the second most common gastrointestinal visceral injury attributable to CPR [12]. Liver lacerations occur most frequently in the left lobe [11, 12]. This could be explained by the close anatomical relationship between the left hepatic lobe and the xiphoid process of the sternum. Two important factors that may aggravate the risk of liver rupture in patients suffering from cardiopulmonary arrest are hepatic ischemia and liver distention due to venous congestion. Another precipitating factor in patients with myocardial infarction is treatment with antiplatelet, antithrombotic and thrombolytic agents $[8,9,14]$.

As intra-abdominal injuries are infrequent complications of CPR, their diagnosis may be difficult and requires careful clinical evaluation as well as regular monitoring of standard hemodynamic and laboratory parameters. Routine implementation of abdominal imaging techniques in every patient after successful CPR seems redundant. In our opinion, a decision to perform an abdominal ultrasound or CT scan should be based on clinical assumptions and premises.

So far, due to insufficient evidence, no unequivocal recommendations for the management of CPRrelated liver injuries have been made. However, according to the guidelines of the Eastern Association for the Surgery of Trauma [15], nonoperative management of blunt hepatic injuries in hemodynamically stable patients is reasonable. In patients with CPR-related liver trauma mortality remains high, irrespective of the treatment received [12], although single reports of successful conservative therapy are available [14]. The scarcity of data makes it difficult to anticipate which patients with CPR-related liver trauma will benefit from surgical intervention.

\section{References}

1. Moore EE, Cogbill TH, Jurkovich GJ, Shackford SR, Malangoni MA, Champion HR. Organ injury scaling: spleen and liver (1994 revision). J Trauma 1995; 38: 323-4.

2. Buschmann CT, Tsokos M. Frequent and rare complications of resuscitation attempts. Intensive Care Med 2009; 35: 397-404.

3. Guldner GT, Schilling TD. Coronary artery occlusion following blunt chest trauma: a case report and review of the literature. CJEM 2005; 7: 118-23.

4. Sato Y, Matsumoto N, Komatsu S, et al. Coronary artery dissection after blunt chest trauma: depiction at multidetector-row computed tomography. Int J Cardiol 2007; 118: 108-10.

5. Lin YL, Yu CH. Acute myocardial infarction caused by coronary artery dissection after a blunt chest trauma. Intern Med 2011; 50: 1969-71.

6. Al-Aqeedi RF, Ali WM, Al-Ani F, Abdulrahman YS, Alnabti A. A blunt chest trauma causing left anterior descending artery dissection and acute myocardial infarction treated by deferred angioplasty. Heart Views 2011; 12: 71-3. 
7. Rosen J, Tuchek JM, Hartmann JR. Liver laceration in the hemodynamically unstable post-cardiac massage patient: early recognition and management - case report. J Trauma 1999; 47: 408-9.

8. Adams HA, Schmitz CS, Block G, Schlichting C. Intraabdominal bleeding after myocardial infarction with cardiopulmonary resuscitation and thrombolytic therapy. Anaesthesist 1995; 44: 585-9.

9. Pezzi A, Pasetti G, Lombardi F, Fiorentini C, lapichino G. Liver rupture after cardiopulmonary resuscitation (CPR) and thrombolysis. Intensive Care Med 1999; 25: 1032.

10. Druw`e PM, Cools FJ, De Raedt HJ, Bossaert LL. Liver rupture after cardiopulmonary resuscitation in a patient receiving thrombolytic therapy. Resuscitation 1996; 32: 213-6.

11. Krischer JP, Fine EG, Davis JH, Nagel EL. Complications of cardiac resuscitation. Chest 1987; 92: 287-91.

12. Meron G, Kurkciyan I, Sterz F, et al. Cardiopulmonary resuscitation-associated major liver injury. Resuscitation 2007; 75: 445-53.

13. Camden JR, Carucci LR. Liver injury diagnosed on computed tomography after use of an automated cardiopulmonary resuscitation device. Emerg Radiol 2011; 18: 429-31.

14. Ziegenfuss MD, Mullany DV. Traumatic liver injury complicating cardio-pulmonary resuscitation. The value of a major intensive care facility: a report of two cases. Crit Care Resusc 2004; 6: 102-4.

15. Eastern Association for the Surgery of Trauma (EAST) Practice Management Guidelines Work Group. Practice Management Guidelines for the Nonoperative $\mathrm{Ma}$ nagement of Blunt Injury to the Liver and Spleen 2003. www.east.org/tpg/livspleen.pdf 